\title{
Ultrasonic-Assisted Synthesis, Characterization, and Optical Properties of Sb Doped ZnO and Their Photocatalytic Activities
}

\author{
Anukorn Phuruangrat, ${ }^{1}$ Waipawan Kongpet, ${ }^{1}$ Oranuch Yayapao, ${ }^{2}$ Budsabong Kuntalue, \\ Somchai Thongtem, ${ }^{2,4}$ and Titipun Thongtem ${ }^{4,5}$ \\ ${ }^{1}$ Department of Materials Science and Technology, Faculty of Science, Prince of Songkla University, Hat Yai, Songkhla 90112, Thailand \\ ${ }^{2}$ Department of Physics and Materials Science, Faculty of Science, Chiang Mai University, Chiang Mai 50200, Thailand \\ ${ }^{3}$ Electron Microscopy Research and Service Center, Faculty of Science, Chiang Mai University, Chiang Mai 50200, Thailand \\ ${ }^{4}$ Materials Science Research Center, Faculty of Science, Chiang Mai University, Chiang Mai 50200, Thailand \\ ${ }^{5}$ Department of Chemistry, Faculty of Science, Chiang Mai University, Chiang Mai 50200, Thailand
}

Correspondence should be addressed to Anukorn Phuruangrat; phuruangrat@hotmail.com and

Somchai Thongtem; schthongtem@yahoo.com

Received 3 September 2013; Revised 21 November 2013; Accepted 4 December 2013; Published 5 February 2014

Academic Editor: Zhenhui Kang

Copyright (C) 2014 Anukorn Phuruangrat et al. This is an open access article distributed under the Creative Commons Attribution License, which permits unrestricted use, distribution, and reproduction in any medium, provided the original work is properly cited.

$\mathrm{Sb}$ doped $\mathrm{ZnO}$ nanostructures were synthesized by an ultrasonic-assisted method. Effect of Sb dopant on the structure, morphology, and composition of as-synthesized Sb doped $\mathrm{ZnO}$ nanostructures was investigated by X-ray diffraction (XRD), scanning electron microscopy (SEM), energy dispersive X-ray (EDX) spectroscopy, and transmission electron microscopy (TEM). All samples were identified to wurtzite hexagonal $\mathrm{ZnO}$ structure. UV-visible spectra of the as-synthesized 3\% Sb doped ZnO sample exhibit broad absorption bands at around $343 \mathrm{~nm}$ which is blue shift of $373 \mathrm{~nm}$ of pure $\mathrm{ZnO}$. The photocatalytic activity was tested by decolorization of methylene blue (MB) solution under UV light. After 300 min irradiation, the degradation efficiencies were 56, 90, and $95 \%$ for $\mathrm{ZnO}, 1 \% \mathrm{Sb}$ doped $\mathrm{ZnO}$, and 3\% Sb doped $\mathrm{ZnO}$, respectively. The 3\% Sb doped $\mathrm{ZnO}$ shows the highest photocatalytic activity than any other samples.

\section{Introduction}

Zinc oxide $(\mathrm{ZnO})$ is a n-type II-VI semiconductor with a wide direct band gap of $3.37 \mathrm{eV}$ and large exciton binding energy of $60 \mathrm{meV}$ [1-5], which is more than other semiconductor materials: $\mathrm{ZnSe}(22 \mathrm{meV})$ and $\mathrm{GaN}(25 \mathrm{meV})$ [6]. It has interesting applications on nanolasers, piezoelectric nanogenerators, solar cells, gas sensors, and photocatalyst, due to its unique optical and electrical properties $[1,2,4$, 7]. However, its electrical and optical properties are not able to completely meet the requirements of constructing high performance semiconducting devices, including the increasing needs for applications nowadays $[1,2,5]$. To enhance these properties, $\mathrm{ZnO}$ was frequently doped with some dopants $[1,2,5]$ such as Sb $[6,8]$, Sn [9], In [10, 11], $\mathrm{Mn}$ [12], and $\mathrm{Ce}$ [13]. Sn doped $\mathrm{ZnO}$ shows the highest gas response to ethanol vapor and highest photocatalytic activity toward methyl orange (MO) solution [9]. The $2 \% \mathrm{Ce}$ doped $\mathrm{ZnO}$ shows an effective oxidation of cyanide to cyanate [13]. Sb doped $\mathrm{ZnO}$ nanoparticles have higher resistance and reflectivity than the undoped ones [8].

In this research, a facile and environment-friendly lowtemperature route was used to synthesize $\mathrm{Sb}$ doped $\mathrm{ZnO}$ by ultrasonic-assisted solution method. Phase, morphologies, optical properties, and photocatalytic properties of Sb doped $\mathrm{ZnO}$ were also studied and discussed in this report.

\section{Experimental Procedures}

$\mathrm{Sb}$ doped $\mathrm{ZnO}$ nanostructures were synthesized by the ultrasonic-assisted solution method using zinc nitrate hexahydrate $\left(\mathrm{Zn}\left(\mathrm{NO}_{3}\right)_{2} \cdot 6 \mathrm{H}_{2} \mathrm{O}\right)$, antimony chloride $\left(\mathrm{SbCl}_{3}\right)$, and ammonium hydroxide $\left(\mathrm{NH}_{4} \mathrm{OH}\right)$ as starting materials. All 
the chemicals for this synthesis were purchased from Aldrich Chemical Corporation and used without further purification.

For the typical experimental procedure, $0.01 \mathrm{~mol}$ of $\mathrm{Zn}\left(\mathrm{NO}_{3}\right)_{2} \cdot 6 \mathrm{H}_{2} \mathrm{O}$ and $1-5 \%$ by mole of $\mathrm{SbCl}_{3}$ were dissolved in $100 \mathrm{~mL}$ of deionized water. Aqueous solution of $28 \%$ ammonium hydroxide was dropped in precursor solutions until reaching the $\mathrm{pH}$ of 8.5 with continuous stirring to precipitate $\mathrm{Zn}^{2+}$ and $\mathrm{Sb}^{3+}$ ions into metal hydroxide compound. Subsequently, the resultant solutions were transferred into sonication bath $(35 \mathrm{kHz})$ and sonicated at $80^{\circ} \mathrm{C}$ for $3 \mathrm{~h}$. In the end, the precipitates were filtered and washed with methanol several times to remove ionic impurities and finally dried at room temperature.

Crystalline phases of the as-synthesized nanostructured materials were analyzed by an X-ray diffractometer (XRD, Philips X'Pert MPD) with $\mathrm{Cu}-\mathrm{K}_{\alpha}$ radiation in the $2 \theta=$ $15^{\circ}-75^{\circ}$ range. The morphology investigation was carried out by field emission scanning electron microscopy (FE-SEM, JEOL JSM-6335F) and transmission electron microscopy (TEM, JEOL JEM-2010) operating at $35 \mathrm{kV}$ and $200 \mathrm{kV}$, respectively. The optical properties were studied by a Perkin Elmer, Lambda 25 UV-visible spectrometer.

Photocatalytic activity was tested by decolorization of methylene blue (MB) in aqueous solution under UV light. The $150 \mathrm{mg}$ pure $\mathrm{ZnO}$ and $\mathrm{Sb}$ doped $\mathrm{ZnO}$ as photocatalysts were suspended in $150 \mathrm{~mL} 10^{-5} \mathrm{M} \mathrm{MB}$ solutions and were magnetically stirred for $30 \mathrm{~min}$ in the dark environment to establish an adsorption/desorption equilibrium of $\mathrm{MB}$ on surfaces of the photocatalysts. After UV irradiating, the concentrations of $\mathrm{MB}$ were determined by a UV-visible spectrophotometer (Lambda 25, Perkin Elmer) using a wavelength of $664 \mathrm{~nm}$. The decolorization efficiency (\%) was calculated as follows:

$$
\text { decolorization efficiency }(\%)=\frac{C_{o}-C}{C_{o}} \times 100
$$

where $C_{o}$ and $C$ were the initial concentration of MB and the concentration of $\mathrm{MB}$ after UV irradiation, respectively.

\section{Results and Discussion}

The purity and crystalline properties of the as-synthesized $\mathrm{ZnO}$ and $\mathrm{Sb}$ doped $\mathrm{ZnO}$ samples were determined by X-ray diffraction (XRD) as shown in Figure 1. The XRD pattern of $\mathrm{ZnO}$ without $\mathrm{Sb}$ dopant showed diffraction peaks at $2 \theta=31.8^{\circ}, 34.5^{\circ}, 36.4^{\circ}, 47.5^{\circ}, 57.1^{\circ}, 63.2^{\circ}, 66.7^{\circ}, 67.8^{\circ}$, and $69.0^{\circ}$, identified to the (100), (002), (101), (102), (110), (103), (200), (112), and (201) planes, respectively, of bulk wurtzite hexagonal $\mathrm{ZnO}$ structure (JCPDS no. 36-1451) [14]. No observed characteristic peaks corresponding to impurities such as $\mathrm{Zn}(\mathrm{OH})_{2}$ were detected in the pattern, confirming the purity of $\mathrm{ZnO}$ sample. XRD patterns of $1-3 \% \mathrm{Sb}$ doped $\mathrm{ZnO}$ show the same diffraction pattern as pure wurtzite hexagonal $\mathrm{ZnO}$ structure with JCPDS no. 36-1451. no diffraction peaks of impurity phases such as $\mathrm{Zn}(\mathrm{OH})_{2}, \mathrm{Sb}_{2} \mathrm{O}_{3}$, and $\mathrm{Sb}$ were detected in these samples, suggesting that $\mathrm{Sb}^{3+}$ ions could uniformly substitute into the $\mathrm{Zn}^{2+}$ sites or interstitial sites of $\mathrm{ZnO}$ lattice by forming $2 \mathrm{Sb}_{\mathrm{Zn}}$ and $\mathrm{V}_{\mathrm{Zn}}$ [3]. Moreover,

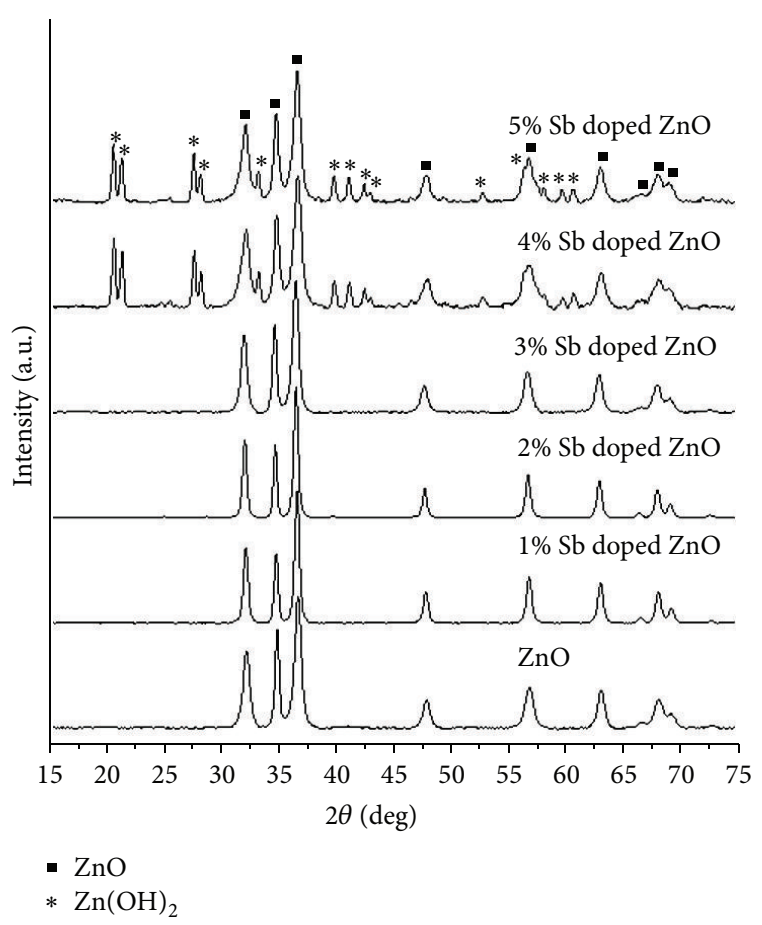

FIGURE 1: XRD patterns of the products synthesized by ultrasonicassisted solution method.

the major diffraction peaks shifted slightly towards smaller diffraction angle compared to the pure $\mathrm{ZnO}$ phase due to the ionic radius of $\mathrm{Sb}^{3+}$ of $0.76 \AA[15,16]>$ ionic radius of $\mathrm{Zn}^{2+}$ of $0.74 \AA[16,17]$. Upon increasing the Sb concentration doped in $\mathrm{ZnO}$ structure of more than 3\%, mixed phases of $\mathrm{Zn}(\mathrm{OH})_{2}$ and $\mathrm{ZnO}$ (JCPDS no. 38-0385 [14] for $\mathrm{Zn}(\mathrm{OH})_{2}$ and no. 361451 [14] for $\mathrm{ZnO}$ ) were detected. The XRD results show that the limited $\mathrm{Sb}$ concentration doped in $\mathrm{ZnO}$ is $3 \mathrm{wt} \%$ in this research.

Figures 2 and 3 show the FE-SEM images of the assynthesized $0-3 \% \mathrm{Sb}$ doped $\mathrm{ZnO}$ products with low and high magnifications. A morphology of pure $\mathrm{ZnO}$ as shown in Figure 2(a) was well-defined flower-like three-dimensional $\mathrm{ZnO}$ nanostructures in a large-scale area with diameters in the range of $0.5-1 \mu \mathrm{m}$. It should be noted that the flowerlike three-dimensional $\mathrm{ZnO}$ nanostructures were composed of assemblies of nanorods as petals. At high magnification image of the nanorod-built flower-like $\mathrm{ZnO}$ nanostructures in Figure 3(a), they revealed that each petal was about $300 \mathrm{~nm}$ long and $100 \mathrm{~nm}$ in diameter. For the SEM images of Sb doped $\mathrm{ZnO}$, the morphologies of rice kernel-like $\mathrm{ZnO}$ nanostructures formed instead of flower-like structures. Figures 2(b), 2(c), and 2(d) and Figures 3(b), 3(c), and 3(d) show SEM images of $1-3 \%$ Sb doped $\mathrm{ZnO}$ prepared by ultrasonicassisted solution method at low and high magnifications. They show the rice kernel-like $\mathrm{ZnO}$ nanorods in the range of $300-400 \mathrm{~nm}$ long. However, no flower-like structures were detected in the $\mathrm{Sb}$ doped $\mathrm{ZnO}$ samples. At high magnification, the products were composed of assembled nanorods to build rice kernel-like $\mathrm{ZnO}$ nanorods. These different morphologies of $\mathrm{ZnO}$ and 1-3\% Sb doped $\mathrm{ZnO}$ can 


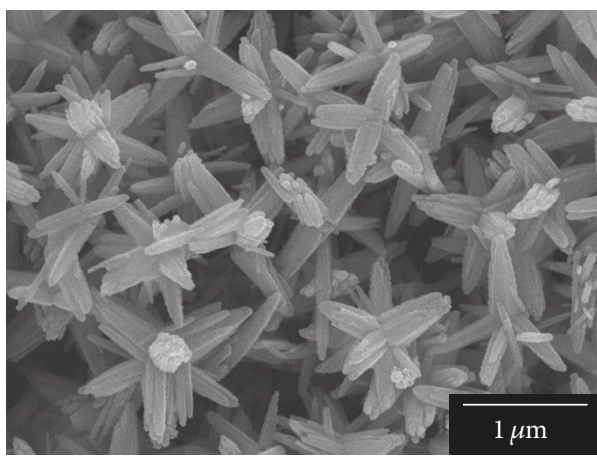

(a)

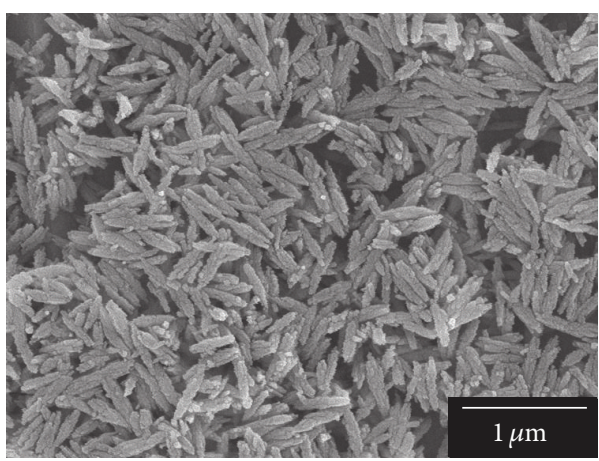

(c)

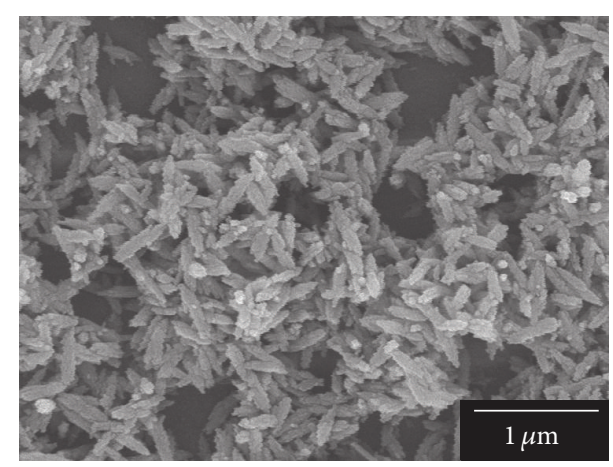

(b)

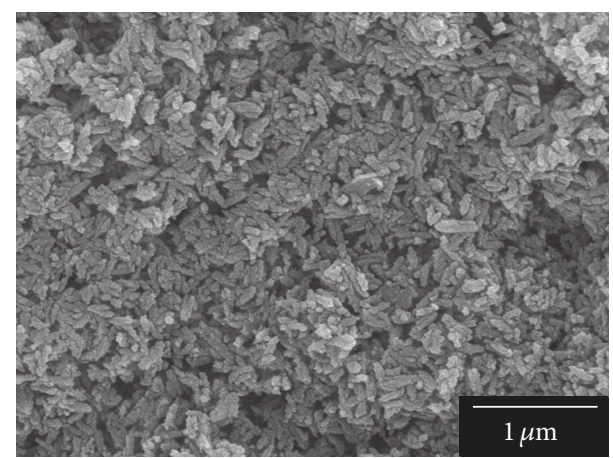

(d)

Figure 2: SEM images of (a) pure ZnO, (b) 1\% Sb doped $\mathrm{ZnO}$, (c) 2\% Sb doped $\mathrm{ZnO}$, and (d) 3\% Sb doped ZnO samples at low magnification.

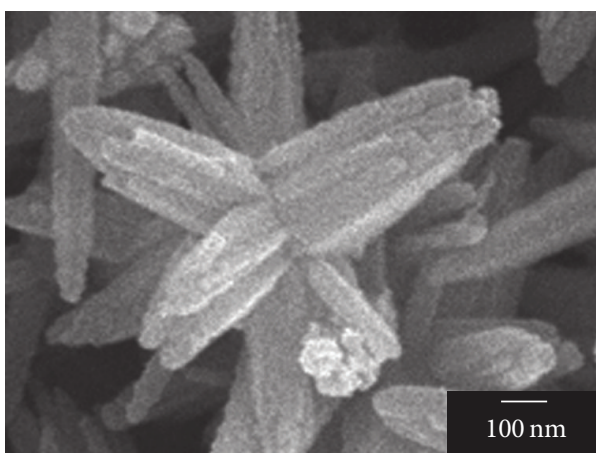

(a)

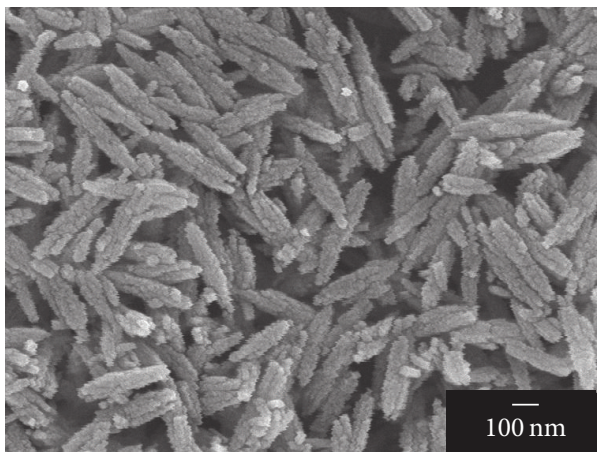

(c)

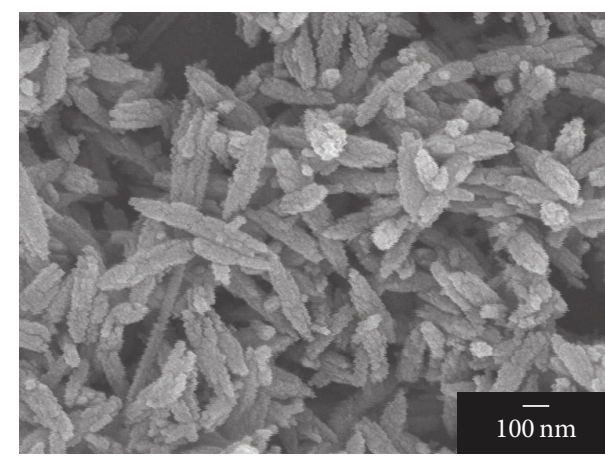

(b)

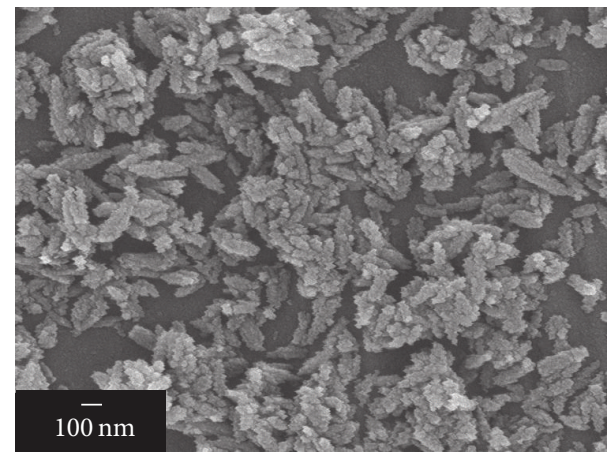

(d)

Figure 3: SEM images of (a) pure ZnO, (b) 1\% Sb doped $\mathrm{ZnO}$, (c) 2\% Sb doped $\mathrm{ZnO}$, and (d) 3\% Sb doped ZnO samples at high magnification. 


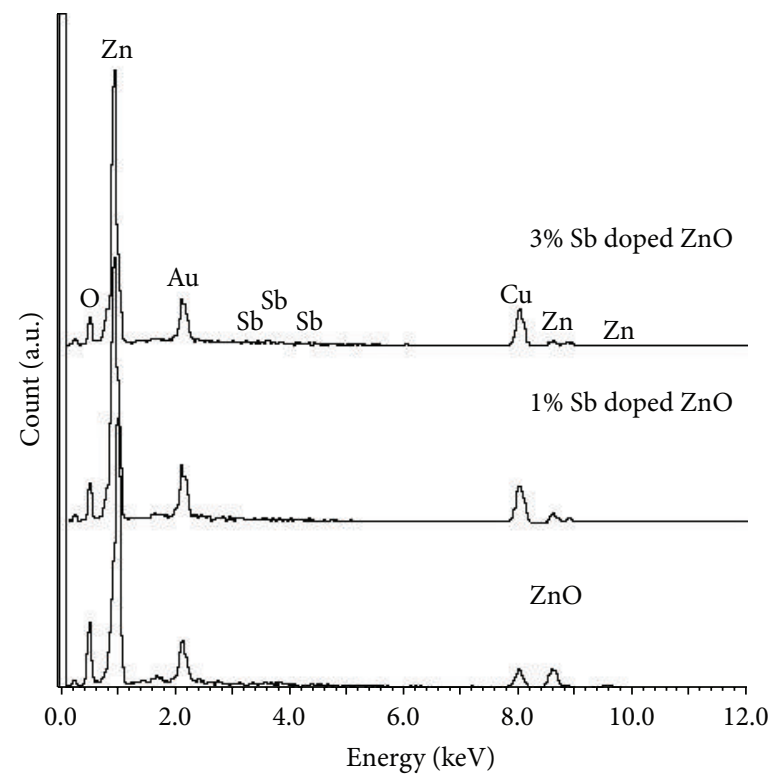

FIGURE 4: EDX spectra of the products synthesized by ultrasonic-assisted solution method.

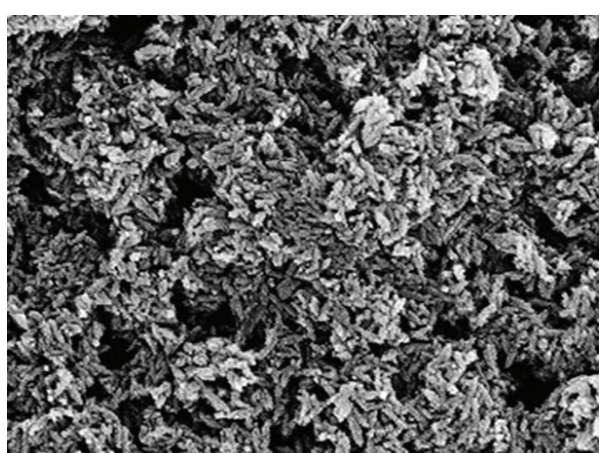

(a)

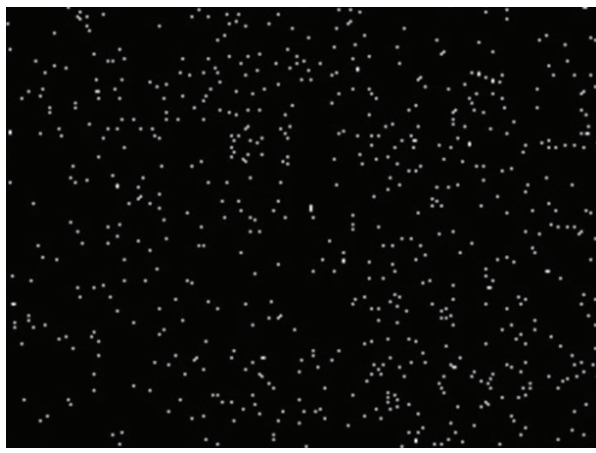

(c)

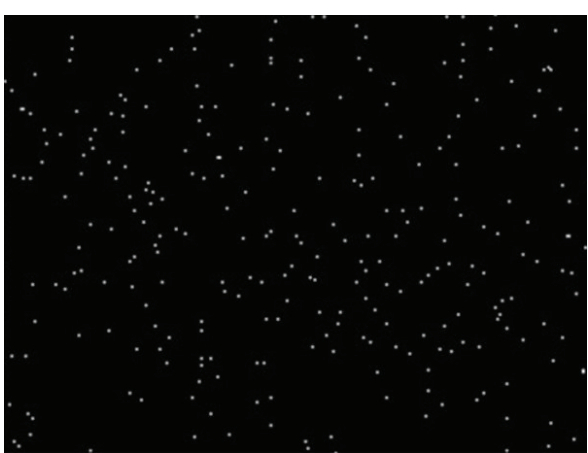

(b)

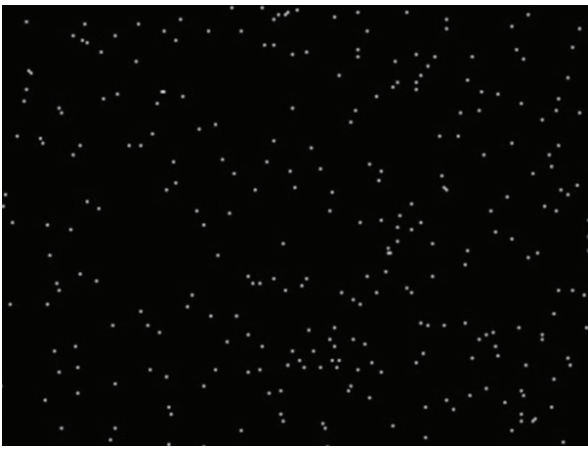

(d)

Figure 5: EDX mapping of 3\% Sb doped $\mathrm{ZnO}$ sample.

be explained in terms of a thermodynamic barrier arising from the $\mathrm{Sb}^{3+}$ dopant that slowed down the nucleation and inhibited the further growth of $\mathrm{Sb}$ doped $\mathrm{ZnO}$ crystals [18].

Chemical composition of the as-synthesized products was observed using EDX analysis. Figures 4 and 5 show the typical EDX spectra of $0-3 \% \mathrm{Sb}$ doped $\mathrm{ZnO}$ and EDX mapping of $3 \% \mathrm{Sb}$ doped $\mathrm{ZnO}$. EDX spectra show that the products consisted of zinc and oxygen for pure $\mathrm{ZnO}$ and zinc, oxygen, and antimony atoms for $1-3 \% \mathrm{Sb}$ doped $\mathrm{ZnO}$. Intense peaks of $\mathrm{Cu}$ and $\mathrm{Au}$ were also detected in the spectra due to the $\mathrm{Cu}$ stubs and sputtered $\mathrm{Au}$. There was no detection of other impurities in the products, indicating that they had very high purity. Figure 5 shows selected area elemental mapping of $3 \% \mathrm{Sb}$ doped $\mathrm{ZnO}$. The mapping was 


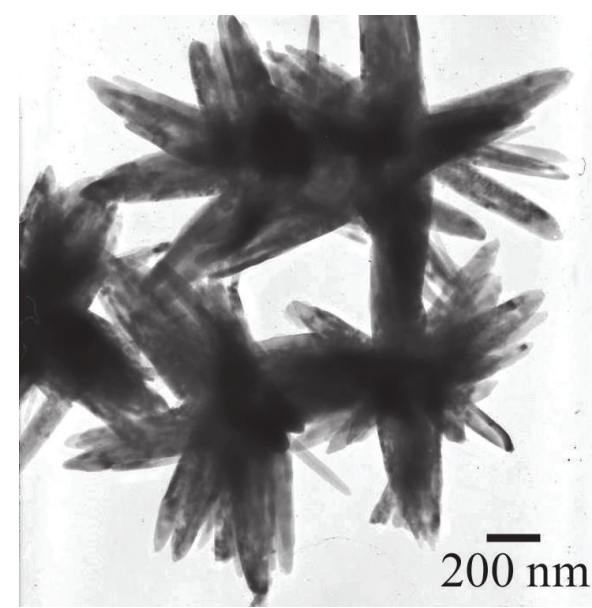

(a)

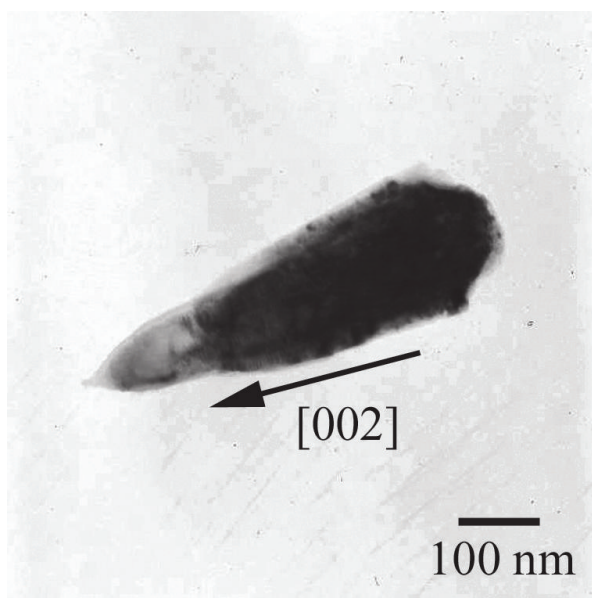

(c)

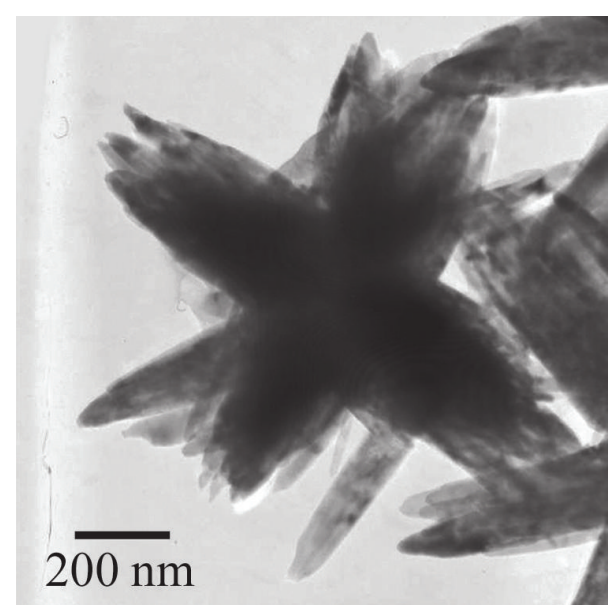

(b)

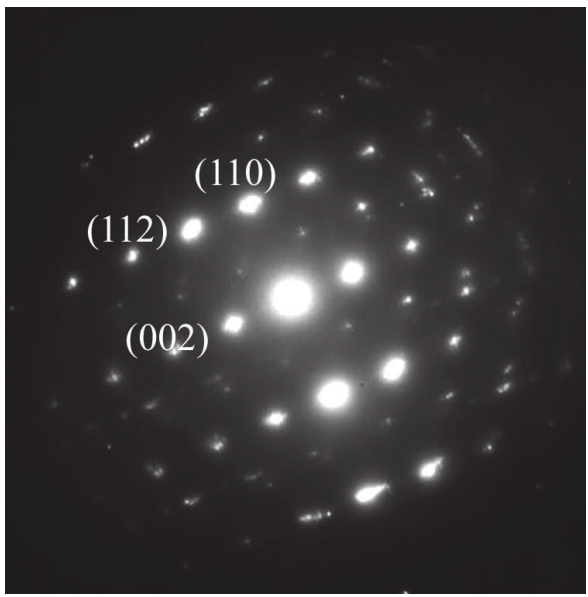

(d)

FIGURE 6: TEM images and SAED pattern of flower-like $\mathrm{ZnO}$ structure.

mainly composed of $\mathrm{Zn}, \mathrm{O}$, and Sb elements. The Sb element was uniformly diffusive in $\mathrm{ZnO}$ lattice.

Figure 6(a) shows a bright-field TEM image of the assynthesized $\mathrm{ZnO}$ sample. It indicates the detailed morphology of the $\mathrm{ZnO}$ product with flower-like shape. As shown in Figure 6(b), it can be clearly seen that the detailed shape of some petals of flower-like $\mathrm{ZnO}$ product was composed of many clusters $\mathrm{ZnO}$ nanorods. These nanorods were in contact with each other as bundles, growing outwardly by forming flower-like structures. The shape of the product appears as flowers with several symmetric petals. It indicated that every bundle was composed of closely packed nanorods with average diameters of around $150 \mathrm{~nm}$. By performing on the individual petal (Figure 6(c)), the selected area electron diffraction (SAED) pattern, as shown in Figure 6(d), indicates that the single petal is single crystal of hexagonal $\mathrm{ZnO}$ phase. The individual petal was also confirmed that the nanorods grow along the [0001] direction.

Regarding the formation of flower-like $\mathrm{ZnO}$, it can be explained by manipulating the growth kinetics. In the present case, the contributing growth-driving force for $\mathrm{ZnO}$ crystals is the concentration of $\mathrm{ZnO}_{2}{ }^{2-}$ monomers. In the reaction solution containing $\mathrm{Zn}\left(\mathrm{NO}_{3}\right)_{2}$ and $\mathrm{NH}_{4} \mathrm{OH}$, the high reactant concentrations led to the burst of initial homogeneous nucleation, and the supersaturated $\mathrm{ZnO}$ nuclei aggregated together in groups. As the reaction proceeded, concentration of the $\mathrm{ZnO}_{2}{ }^{2-}$ monomers became lower. Some active sites on the surface of the initially formed $\mathrm{ZnO}$ aggregates grew along the oriented direction as the chemical environment constantly provided reactants. Due to the intrinsic anisotropy in its growth rate $(\nu)$ with $v[0001] \gg v[01-10]>v[000-1]$, the preferential growth of the product is along the [0001] direction $[7,19]$. The structure of $\mathrm{ZnO}$ single crystal can be described as a number of alternating planes of coordinated $\mathrm{O}^{2-}$ and $\mathrm{Zn}^{2+}$ ions. The oppositely charged ions are made of the positively charged $\mathrm{Zn-(0001)}$ and negatively charged $\mathrm{O}$ (0001) polar surfaces. Following the decrease of the concentration of $\mathrm{ZnO}_{2}{ }^{2-}$ monomers due to the initial fast nucleation of $\mathrm{ZnO}$, the absorption of $\mathrm{OH}^{-}$on the positively charged $\mathrm{Zn}$ (0001) plane dominated the $\mathrm{ZnO}_{2}{ }^{2-}$ growth units. Therefore, the superfluous $\mathrm{OH}^{-}$ions stabilized the surface charge and the structure of $\mathrm{Zn}$-(0001) face to some degree, allowing 


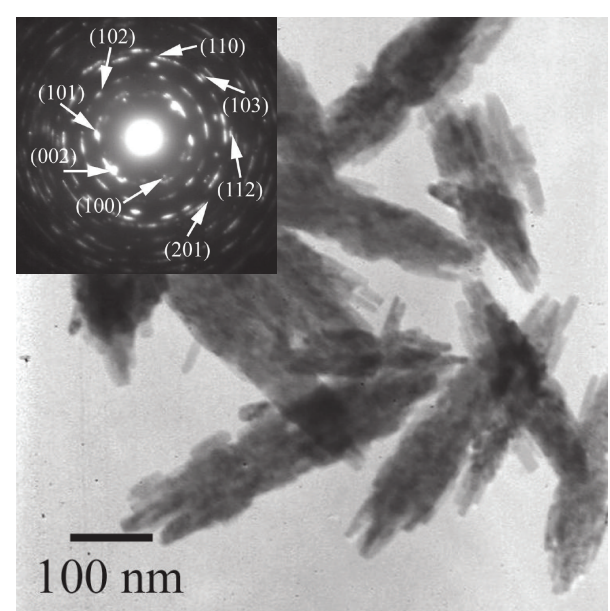

(a)

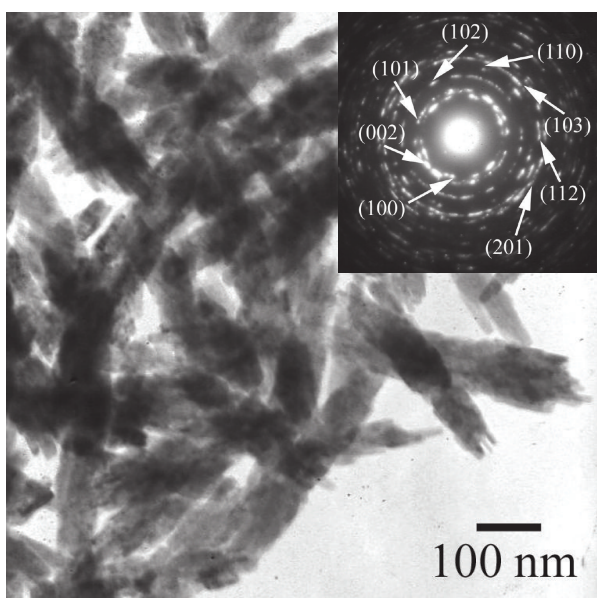

(c)

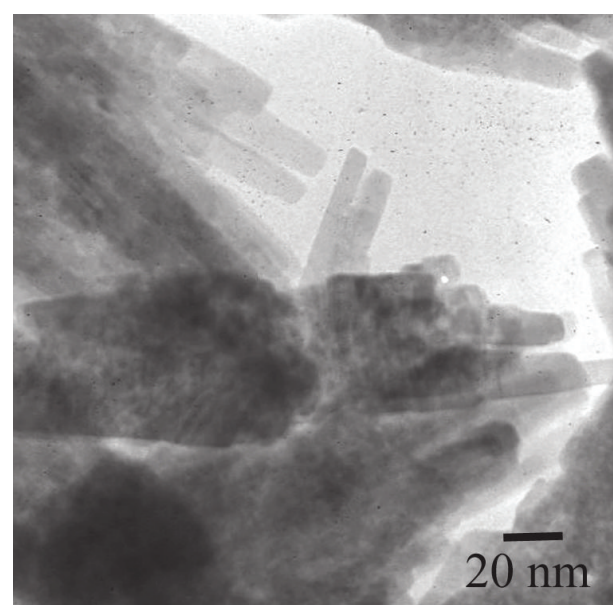

(b)

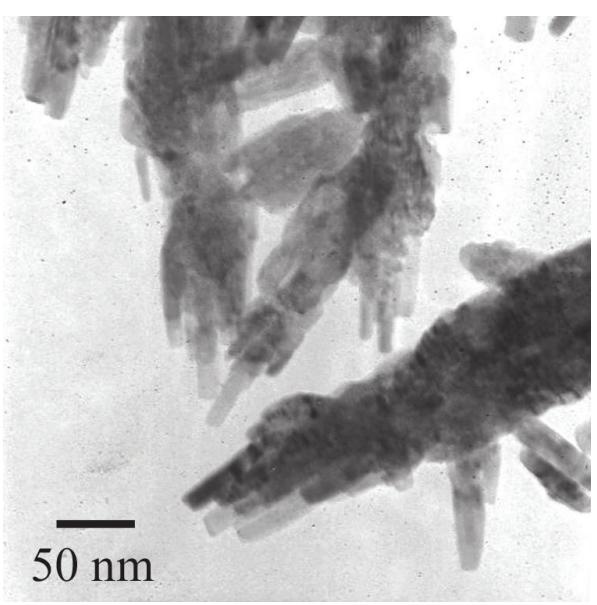

(d)

Figure 7: TEM images and SAED patterns of (a) and (b) 1\% Sb doped ZnO, and (c) and (d) 3\% Sb doped ZnO samples.

the fast growth along the [0001] direction, leading to the formation of flower-like $\mathrm{ZnO}$ nanostructure [7, 20-22].

Figure 7 shows the typical TEM images of $1 \%$ and 3\% $\mathrm{Sb}$ doped $\mathrm{ZnO}$ nanostructures. It is apparent that $1 \% \mathrm{Sb}$ doped $\mathrm{ZnO}$ exhibits well-defined rice kernel-like colonies with an average size of $300-400 \mathrm{~nm}$. The nanorods serving as building blocks were tightly packed as colonies of rice kernel-like shaped particles. It can be concluded that the rice kernel-like $\mathrm{ZnO}$ colonies formed from the attachment of $\mathrm{ZnO}$ nanorods. The magnified TEM image in Figure 7(b) shows the detailed colonies of rice kernel-like $\mathrm{ZnO}$. The colonies of rice kernels were composed of densely arrayed nanorods with diameter of about $10 \mathrm{~nm}$. While the colonies of the 3\% Sb doped $\mathrm{ZnO}$ nanocrystallites as shown in Figure 7(c) present the rice kernel-like colonies of many closely packed nanorods of about $90 \mathrm{~nm}$ in diameter and $1.2 \mu \mathrm{m}$ in length similar to $1 \% \mathrm{Sb}$ doped $\mathrm{ZnO}$ sample. It also shows that the ends of the nanorods have relatively smaller diameters compared to those of the middle parts. The enlarged TEM image of 3\% Sb doped $\mathrm{ZnO}$ sample as shown in Figure 7(d) shows the colonies of rice kernel-like $\mathrm{ZnO}$ particles with very rough surface. It is noteworthy that the rice kernel-like structure was sufficiently stable, which cannot be destroyed even after ultrasonication for a long time. The insets of Figures 7(a) and 7(c) show the SAED pattern taken from their corresponding rice kernel-like $\mathrm{Sb}$-doped $\mathrm{ZnO}$ samples. The diffraction patterns were composed of a number of bright spots arranged in concentric rings, with the calculated lattice planes obtained from the diameters of the diffraction rings. For the present research, the products were polycrystalline in nature. They were the (100), (002), (101), (102), (110), (103), (112), and (201) planes which were in accordance with those of the JCPDS database for hexagonal $\mathrm{ZnO}$ phase.

The optical properties of as-synthesized $0-3 \% \mathrm{Sb}$ doped $\mathrm{ZnO}$ samples were studied by UV-visible absorption as shown in Figure 8. The spectrum of pure phase $\mathrm{ZnO}$ sample exhibits a broad absorption band at around $373 \mathrm{~nm}$, blue shift relative to $380 \mathrm{~nm}$ of bulk $\mathrm{ZnO}$ [23]. However, the spectra of $1 \%$, $2 \%$, and $3 \% \mathrm{Sb}$ doped $\mathrm{ZnO}$ samples exhibit sharp bands at $356 \mathrm{~nm}, 350 \mathrm{~nm}$, and $343 \mathrm{~nm}$, respectively. It should be noted that the absorption peaks became sharper. They were blue-shift from $373 \mathrm{~nm}$ of pure $\mathrm{ZnO}$ sample to $343 \mathrm{~nm}$ of 


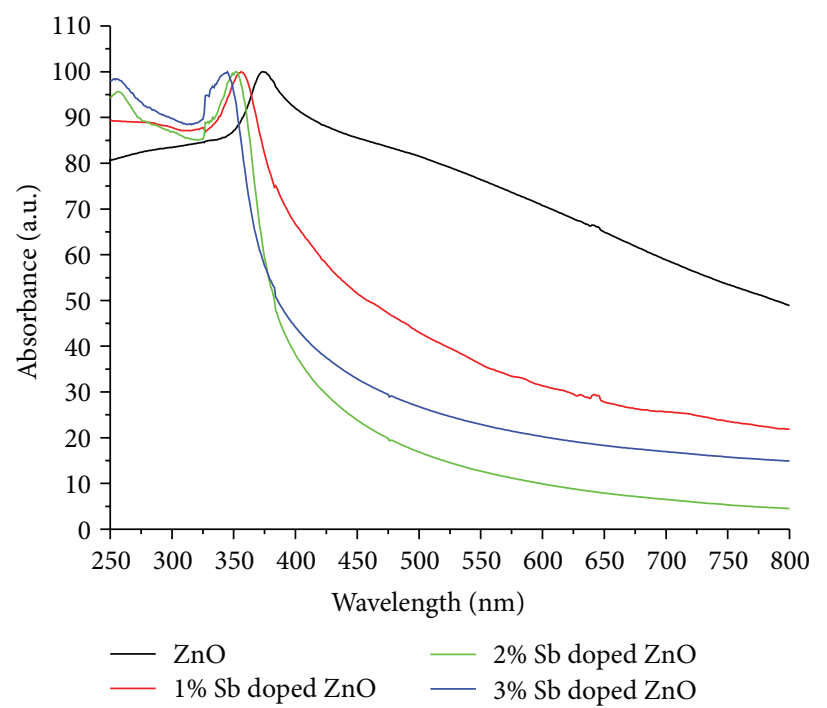

FIGURE 8: UV-visible spectra of as-synthesized 0-3\% $\mathrm{Sb}$ doped $\mathrm{ZnO}$ samples.

3\% $\mathrm{Sb}$ doped $\mathrm{ZnO}$ sample. The band gaps were calculated by the equation of $E_{g}=1240 / \lambda[24,25]$. They are $3.32 \mathrm{eV}$, $3.48 \mathrm{eV}, 3.54 \mathrm{eV}$, and $3.61 \mathrm{eV}$ for $\mathrm{ZnO}, 1 \% \mathrm{Sb}$ doped $\mathrm{ZnO}, 2 \%$ $\mathrm{Sb}$ doped $\mathrm{ZnO}$, and $3 \% \mathrm{Sb}$ doped $\mathrm{ZnO}$, respectively. These can be explained by the decreasing in size of the particles and consequently the increasing band gap between the valence and conduction bands. A blue shift of the absorption peak in the UV-visible spectra of these samples was successfully and clearly observed.

Upon the illumination of UV light, $\mathrm{ZnO}$ can transform the photonic energy into chemical energy, in a similar way for the synthesis or the decomposition of organic materials. Its remarkable oxidation reduction capability, high chemical stability, and harmless characteristics are most commonly applied in pollutant removal and disinfectants. When the $\mathrm{ZnO}$ samples are illuminated by ultraviolet of wavelength less than $400 \mathrm{~nm}$, electrons of the valence band were excited by the photonic energy of the ultraviolet to the conduction band. At the same time, the valence band created electronic holes carrying positive electricity. These holes reacted with the absorbed $\mathrm{O}_{2}$ or $\mathrm{H}_{2} \mathrm{O}$ to create $\mathrm{OH}^{\bullet}$ free radicals, which further generated the reaction such as disinfection or deodorization [26]. Figure 9(a) shows the UV-visible absorption spectral change of $\mathrm{MB}$ during the photocatalytic degradation in the presence of $\mathrm{ZnO}$ under UV light over the wavelength range of 400-800 $\mathrm{nm}$. The intensity of main absorption peaks of the MB solutions at approximately $664 \mathrm{~nm}$ decreases continuously with the length of UV irradiation time. It indicates that $\mathrm{MB}$ molecules could be degraded in the presence of $\mathrm{ZnO}$. The photocatalytic mechanism of $\mathrm{ZnO}$ is as follows:

$$
\begin{gathered}
\mathrm{ZnO}+\mathrm{hv} \longrightarrow \mathrm{ZnO}\left(\mathrm{e}_{\mathrm{CB}}{ }^{-}+\mathrm{h}_{\mathrm{VB}}{ }^{+}\right) \\
\mathrm{H}_{2} \mathrm{O}+\mathrm{h}_{\mathrm{VB}}{ }^{+} \longrightarrow \mathrm{H}^{+}+\mathrm{OH}^{\cdot}
\end{gathered}
$$

dye $+\mathrm{OH}^{\bullet} \longrightarrow$ oxidation products where $\mathrm{h}_{\mathrm{VB}}{ }^{+}$and $\mathrm{e}_{\mathrm{CB}}{ }^{-}$are the electron vacancies in the valence band and the photogenerated electrons in the conduction band, respectively. The conduction-band electrons and valence-band holes are generated on the surfaces of $\mathrm{ZnO}$ nanostructures when they are illuminated by UV light with energy greater than the band gap. Holes react with water molecules adhering to the surfaces of $\mathrm{ZnO}$ nanostructures to form highly reactive hydroxyl radicals $\left(\mathrm{OH}^{\bullet}\right)$ which have a powerful oxidation ability to degrade organic dye [7]. Figures 9(b) and 9(c) show the UV-visible absorption spectra of the aqueous solutions of $\mathrm{MB}$ with $1 \% \mathrm{Sb}$ doped $\mathrm{ZnO}$ and 3\% Sb doped $\mathrm{ZnO}$ samples as photocatalysts and illuminated to UV light for different time intervals. The characteristic absorption of $\mathrm{MB}$ at $664 \mathrm{~nm}$ decreases rapidly with the prolonging time and almost disappears after about $300 \mathrm{~min}$. Further exposure leads to no absorption peak in the whole spectrum, indicating that almost none of the MB remain. These photocatalysis results clearly demonstrate that $\mathrm{Sb}$ doped $\mathrm{ZnO}$ exhibited higher photocatalytic activity as compared with $\mathrm{ZnO}$ sample.

Figure 10 shows $\mathrm{MB}$ degradation efficiency of the assynthesized $\mathrm{ZnO}$ and $\mathrm{Sb}$ doped $\mathrm{ZnO}$ samples. The Sb doped $\mathrm{ZnO}$ samples exhibit much higher photocatalytic activities than that of the pure $\mathrm{ZnO}$ one. It took only $102 \mathrm{~min}$ for 3\% Sb doped $\mathrm{ZnO}$ and $134 \mathrm{~min}$ for $1 \% \mathrm{Sb}$ doped $\mathrm{ZnO}$ to decolorize $50 \%$ of $\mathrm{MB}$ while pure $\mathrm{ZnO}$ took more than $275 \mathrm{~min}$ to decolorize the same amount of MB. This faster degradation rate of $\mathrm{MB}$ under $\mathrm{UV}$ irradiation using $\mathrm{Sb}$ doped $\mathrm{ZnO}$ is attributed to the increase in defect sites caused by $\mathrm{Sb}^{3+}$ doping, leading to an enhanced optical absorption in the UV region. After $300 \mathrm{~min}$ of irradiation, the values of degradation efficiency are 56, 90, and $95 \%$ for pure $\mathrm{ZnO}, 1 \% \mathrm{Sb}$ doped $\mathrm{ZnO}$, and $3 \% \mathrm{Sb}$ doped $\mathrm{ZnO}$, respectively. This clearly demonstrates that $\mathrm{ZnO}$ doped with $\mathrm{Sb}^{3+}$ degrades $\mathrm{MB}$ more efficiently than undoped $\mathrm{ZnO}$. In this research, the $3 \% \mathrm{Sb}$ doped $\mathrm{ZnO}$ shows the highest photocatalytic activity. Under illumination with UV light, Sb doped $\mathrm{ZnO}$ generates electron-hole pairs at the tail states of conduction and valence bands. The generated 


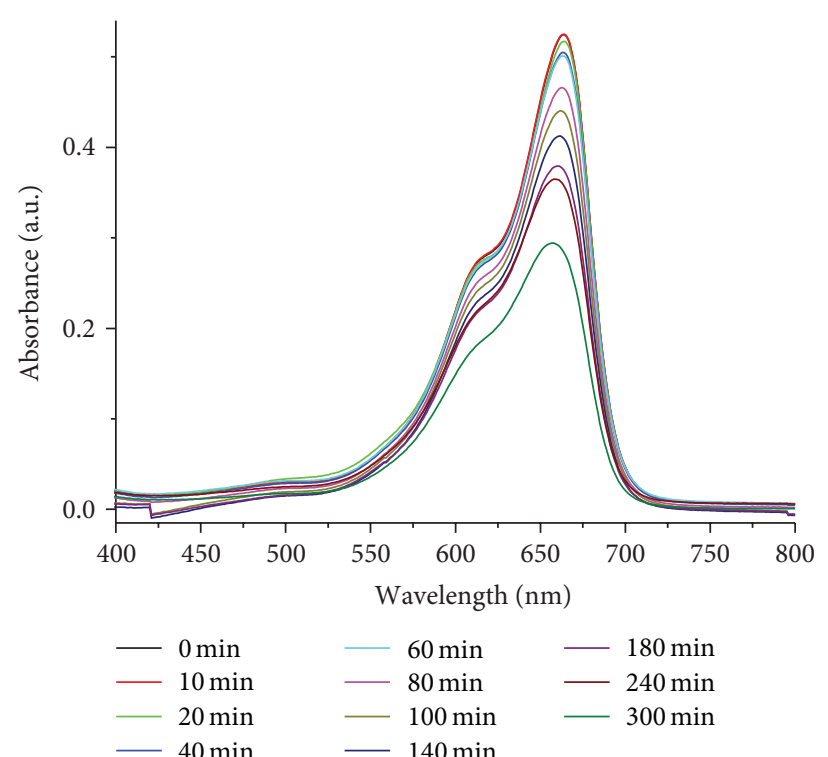

(a)

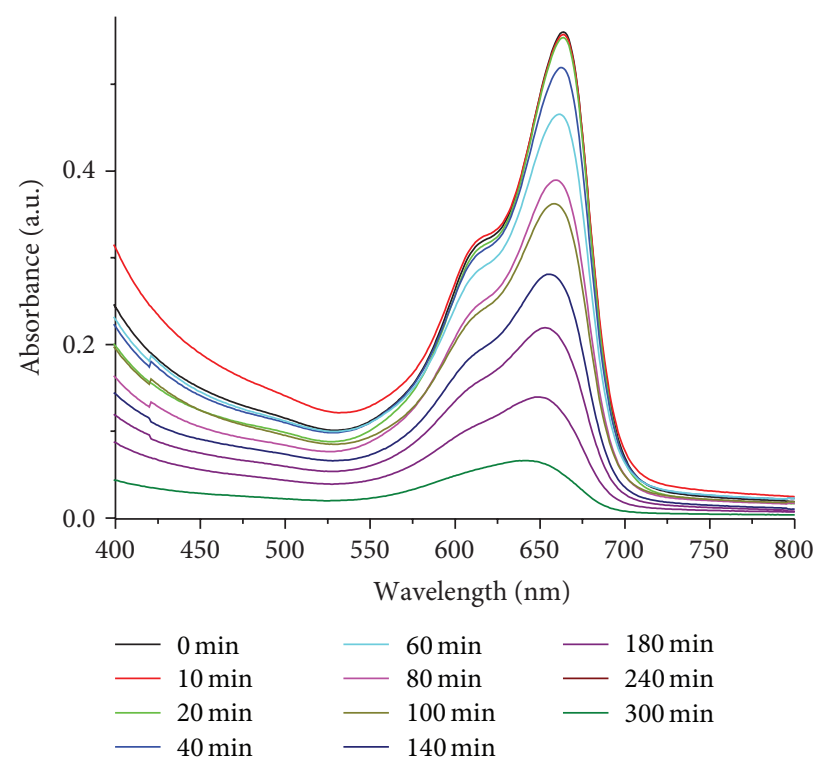

(b)

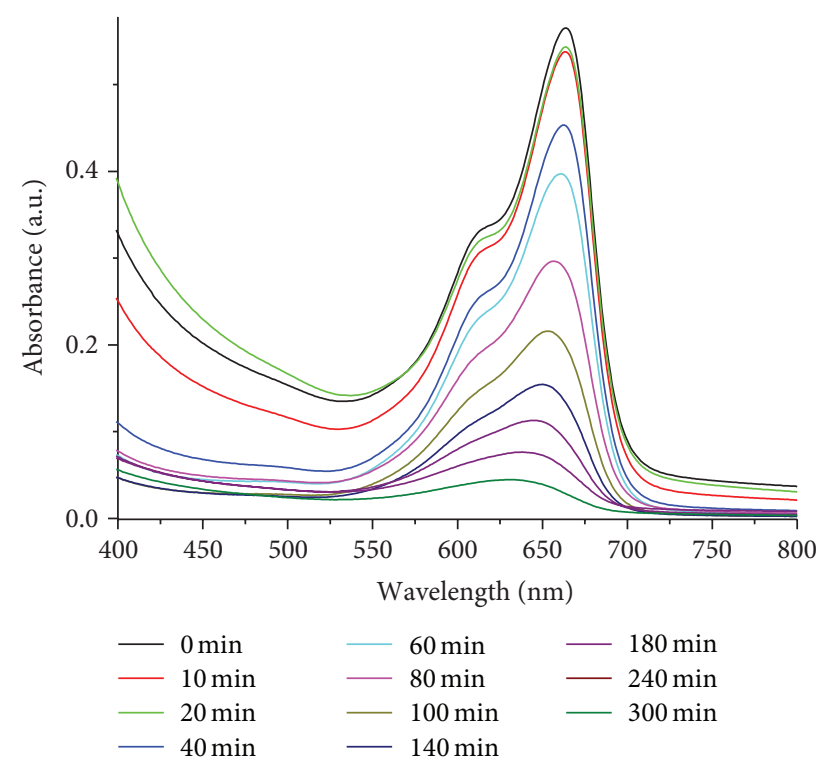

(c)

Figure 9: UV-visible absorption of MB solutions containing (a) $\mathrm{ZnO}$, (b) $1 \% \mathrm{Sb}$ doped $\mathrm{ZnO}$ and (c) 3\% Sb doped $\mathrm{ZnO}$.

electrons diffused to the adsorbed MB molecules on the surface of $\mathrm{Sb}$ doped $\mathrm{ZnO}$. The excited electrons from the photocatalyst conduction band migrated into the molecular structure of $\mathrm{MB}$ and by forming the conjugated system which then led to the complete decomposition of MB. Holes at the valence band generated $\mathrm{OH}^{\cdot}$ via reaction with water or $\mathrm{OH}^{-}$ might be used for oxidation of other organic compounds.

The photocatalytic properties of as-synthesized photocatalysts were evaluated by measuring the absorption intensity of MB at $664 \mathrm{~nm}$ after UV irradiation at different lengths of time. Both of these photodegradation reactions were determined by pseudo-first-order reactions [27-30]. The reaction rate constants of $\mathrm{MB}$ degradation calculated for $\mathrm{ZnO}, 1 \% \mathrm{Sb}$ doped $\mathrm{ZnO}$, and $3 \% \mathrm{Sb}$ doped $\mathrm{ZnO}$ are $1.47 \times 10^{-3}, 6.30 \times 10^{-3}$, and $8.65 \times 10^{-3} \mathrm{~min}^{-1}$, respectively. This clearly demonstrates that $\mathrm{ZnO}$ doped with antimony can be used as a potential photocatalyst illuminated with UV light.

\section{Conclusions}

Ultrasonic-assisted synthesis of $\mathrm{Sb}$ doped $\mathrm{ZnO}$ at room temperature has been introduced. XRD results showed the formation of wurtzite $\mathrm{ZnO}$ and the upper bound of $3 \mathrm{wt} \%$ doped Sb. No other phases were detected. The amount of 


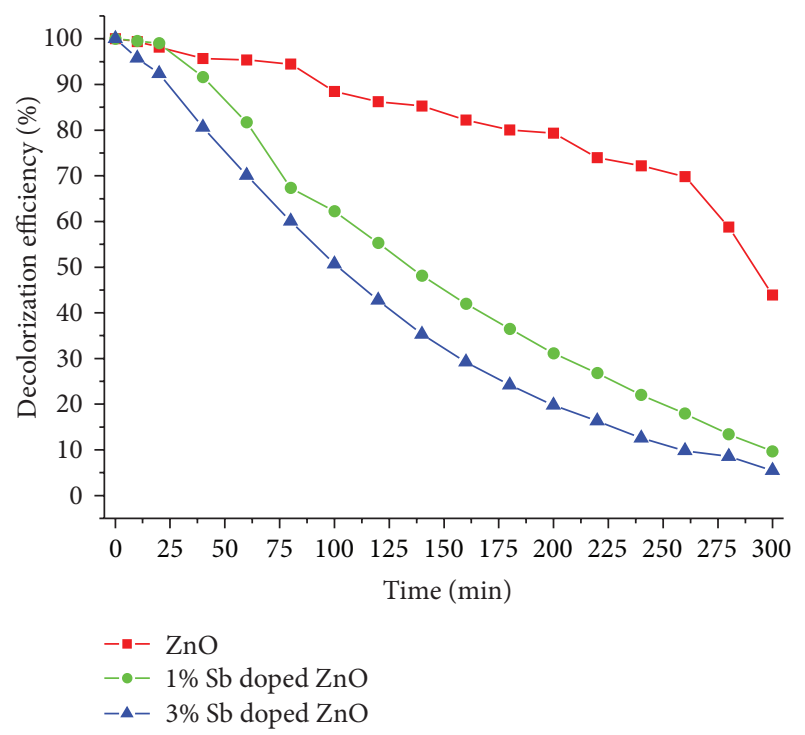

FIGURE 10: Decolorization efficiencies of $\mathrm{ZnO}$ with and without $\mathrm{Sb}$ doping.

antimony added shows a profound effect on morphology which changed from flower-like structure of nanorods for $\mathrm{ZnO}$ to rice kernel-like structure for $\mathrm{Sb}$ doped $\mathrm{ZnO}$. Assynthesized doped and undoped $\mathrm{ZnO}$ crystals were tested and compared for their photocatalytic activities by decolorization of MB under UV light. It was clear that $3 \% \mathrm{Sb}$ doped $\mathrm{ZnO}$ showed the highest photocatalytic activity toward the MB solution.

\section{Conflict of Interests}

The authors declare that there is no conflict of interests regarding the publication of this paper.

\section{Acknowledgment}

The authors wish to thank the Thailand Research Fund (TRF) for providing financial support through the TRF research Contract MRG5580112.

\section{References}

[1] W.-W. Zhong, F.-M. Liu, L.-G. Cai, X.-Q. Liu, and Y. Li, "Effect of growth time on the structure, Raman shift and photoluminescence of $\mathrm{Al}$ and $\mathrm{Sb}$ codoped $\mathrm{ZnO}$ nanorod ordered array thin films," Applied Surface Science, vol. 257, no. 22, pp. 9318-9322, 2011.

[2] D. W. Zeng, C. S. Xie, B. L. Zhu, W. L. Song, and A. H. Wang, "Synthesis and characteristics of Sb-doped $\mathrm{ZnO}$ nanoparticles," Materials Science and Engineering B, vol. 104, no. 1-2, pp. 68-72, 2003.

[3] X. Fang, J. Li, D. Zhao et al., "Structural and photoluminescence properties of aligned $\mathrm{Sb}$-doped $\mathrm{ZnO}$ nanocolumns synthesized by the hydrothermal method," Thin Solid Films, vol. 518, no. 20, pp. 5687-5689, 2010.
[4] C. H. Zang, J. F. Su, B. Wang, D. M. Zhang, and Y. S. Zhang, "Photoluminescence of $\mathrm{ZnO}$ :Sb nanobelts fabricated by thermal evaporation method," Journal of Luminescence, vol. 131, no. 8, pp. 1817-1820, 2011.

[5] W.-W. Zhong, F.-M. Liu, and W.-P. Chen, "Effect of ammonia/zinc nitrate molar ratio on structural and optical properties of $\mathrm{Al}$ and $\mathrm{Sb}$ codoped $\mathrm{ZnO}$ nanorod ordered array thin films," Journal of Alloys and Compounds, vol. 531, pp. 59-63, 2012.

[6] S. H. Kim, A. Umar, Y. K. Park, J.-H. Kim, E. W. Lee, and Y. B. Hahn, "Non-catalytic growth of high-aspect-ratio Sb-doped $\mathrm{ZnO}$ nanowires by simple thermal evaporation process: structural and optical properties," Journal of Alloys and Compounds, vol. 479, no. 1-2, pp. 290-293, 2009.

[7] B. Li and Y. Wang, "Facile synthesis and enhanced photocatalytic performance of flower-like $\mathrm{ZnO}$ hierarchical microstructures," Journal of Physical Chemistry C, vol. 114, no. 2, pp. 890896, 2010.

[8] D. W. Zeng, C. S. Xie, B. L. Zhu et al., "Controlled growth of $\mathrm{ZnO}$ nanomaterials via doping Sb," Journal of Crystal Growth, vol. 266, no. 4, pp. 511-518, 2004.

[9] X. Jia, H. Fan, M. Afzaal, X. Wu, and P. O’brien, "Solid state synthesis of tin-doped $\mathrm{ZnO}$ at room temperature: characterization and its enhanced gas sensing and photocatalytic properties," Journal of Hazardous Materials, vol. 193, pp. 194-199, 2011.

[10] E. Pál, V. Hornok, A. Oszkó, and I. Dékány, "Hydrothermal synthesis of prism-like and flower-like $\mathrm{ZnO}$ and indium-doped ZnO structures," Colloids and Surfaces A, vol. 340, no. 1-3, pp. $1-9,2009$.

[11] B. Wang, M. J. Callahan, C. Xu, L. O. Bouthillette, N. C. Giles, and D. F. Bliss, "Hydrothermal growth and characterization of indium-doped-conducting $\mathrm{ZnO}$ crystals," Journal of Crystal Growth, vol. 304, no. 1, pp. 73-79, 2007.

[12] C. Jing, Y. Jiang, W. Bai, J. Chu, and A. Liu, "Synthesis of Mndoped $\mathrm{ZnO}$ diluted magnetic semiconductors in the presence of ethyl acetoacetate under solvothermal conditions," Journal of Magnetism and Magnetic Materials, vol. 322, no. 16, pp. 23952400, 2010.

[13] C. Karunakaran, P. Gomathisankar, and G. Manikandan, "Preparation and characterization of antimicrobial Ce-doped $\mathrm{ZnO}$ nanoparticles for photocatalytic detoxification of cyanide," Materials Chemistry and Physics, vol. 123, no. 2-3, pp. 585-594, 2010.

[14] Powder Diffract. File, JCPDS Internat. Centre Diffract. Data, PA 19073-3273, U.S.A., 2001.

[15] M. Dondi, F. Matteucci, and G. Cruciani, "Zirconium titanate ceramic pigments: crystal structure, optical spectroscopy and technological properties," Journal of Solid State Chemistry, vol. 179, no. 1, pp. 233-246, 2006.

[16] O. Lupan, L. Chow, L. K. Ono et al., "Synthesis and characterization of ag- or sb-doped zno nanorods by a facile hydrothermal route," Journal of Physical Chemistry C, vol. 114, no. 29, pp. 12401-12408, 2010.

[17] Y. Yang, J. Qi, Q. Liao, Y. Zhang, L. Tang, and Z. Qin, "Synthesis and characterization of Sb-doped $\mathrm{ZnO}$ nanobelts with singleside zigzag boundaries," Journal of Physical Chemistry C, vol. 112, no. 46, pp. 17916-17919, 2008.

[18] P. Li, S. Wang, J. Li, and Y. Wei, "Structural and optical properties of Co-doped $\mathrm{ZnO}$ nanocrystallites prepared by a one-step solution route," Journal of Luminescence, vol. 132, no. 1, pp. $220-$ 225, 2012. 
[19] R. B. Peterson, C. L. Fields, and B. A. Gregg, "Epitaxial chemical deposition of $\mathrm{ZnO}$ nanocolumns from $\mathrm{NaOH}$ solutions," Langmuir, vol. 20, no. 12, pp. 5114-5118, 2004.

[20] Y. Zeng, T. Zhang, L. Wang, and R. Wang, "Synthesis and ethanol sensing properties of self-assembled monocrystalline $\mathrm{ZnO}$ nanorod bundles by poly(ethylene glycol)-assisted hydrothermal process," Journal of Physical Chemistry C, vol. 113, no. 9, pp. 3442-3448, 2009.

[21] Z. L. Wang, "Novel zinc oxide nanostructures discovery by electron microscopy," Journal of Physics, vol. 26, no. 1, pp. 1-6, 2006.

[22] A. Phuruangrat, T. Thongtem, B. Kuntalue, and S. Thongtem, "Microwave-assisted synthesis and characterization of rose-like and flower-like zinc oxide nanostructures," Journal of Ovonic Research, vol. 7, pp. 107-113, 2011.

[23] J.-S. Liu, J.-M. Cao, Z.-Q. Li, G.-B. Ji, and M.-B. Zheng, "A simple microwave-assisted decomposing route for synthesis of $\mathrm{ZnO}$ nanorods in the presence of PEG400," Materials Letters, vol. 61, no. 22, pp. 4409-4411, 2007.

[24] Y. Lei, G. Zhao, M. Liu, Z. Zhang, X. Tong, and T. Cao, "Fabrication, characterization, and photoelectrocatalytic application of $\mathrm{ZnO}$ nanorods grafted on vertically aligned $\mathrm{TiO}_{2}$ nanotubes," Journal of Physical Chemistry C, vol. 113, no. 44, pp. 19067-19076, 2009.

[25] H. Li, D. Wang, H. Fan, T. Jiang, X. Li, and T. Xie, "Synthesis of ordered multivalent $\mathrm{Mn}-\mathrm{TiO}_{2}$ nanospheres with tunable size: a high performance visible-light photocatalyst," Nano Research, vol. 4, no. 5, pp. 460-469, 2011.

[26] H. Chang and M.-H. Tsai, "Synthesis and characterization of $\mathrm{ZnO}$ nanoparticles having prism shape by a novel gas condensation process," Reviews on Advanced Materials Science, vol. 18, no. 8, pp. 734-743, 2008.

[27] J. Zhao, L. Wang, X. Yan et al., "Structure and photocatalytic activity of Ni-doped $\mathrm{ZnO}$ nanorods," Materials Research Bulletin, vol. 46, no. 8, pp. 1207-1210, 2011.

[28] J. H. Zeng, B. B. Jin, and Y. F. Wang, "Facet enhanced photocatalytic effect with uniform single-crystalline zinc oxide nanodisks," Chemical Physics Letters, vol. 472, no. 1-3, pp. 9095, 2009.

[29] R. Jain and S. Sikarwar, "Photodestruction and COD removal of toxic dye erioglaucine by $\mathrm{TiO}_{2}$-UV process: influence of operational parameters," International Journal of Physical Sciences, vol. 3, no. 12, pp. 299-305, 2008.

[30] J. Chanathaworn, C. Bunyakan, W. Wiyaratn, and J. Chungsiriporn, "Photocatalytic decolorization of basic dye by $\mathrm{TiO}_{2}$ nanoparticle in photoreactor," Songklanakarin Journal of Science and Technology, pp. 203-210, 2012. 

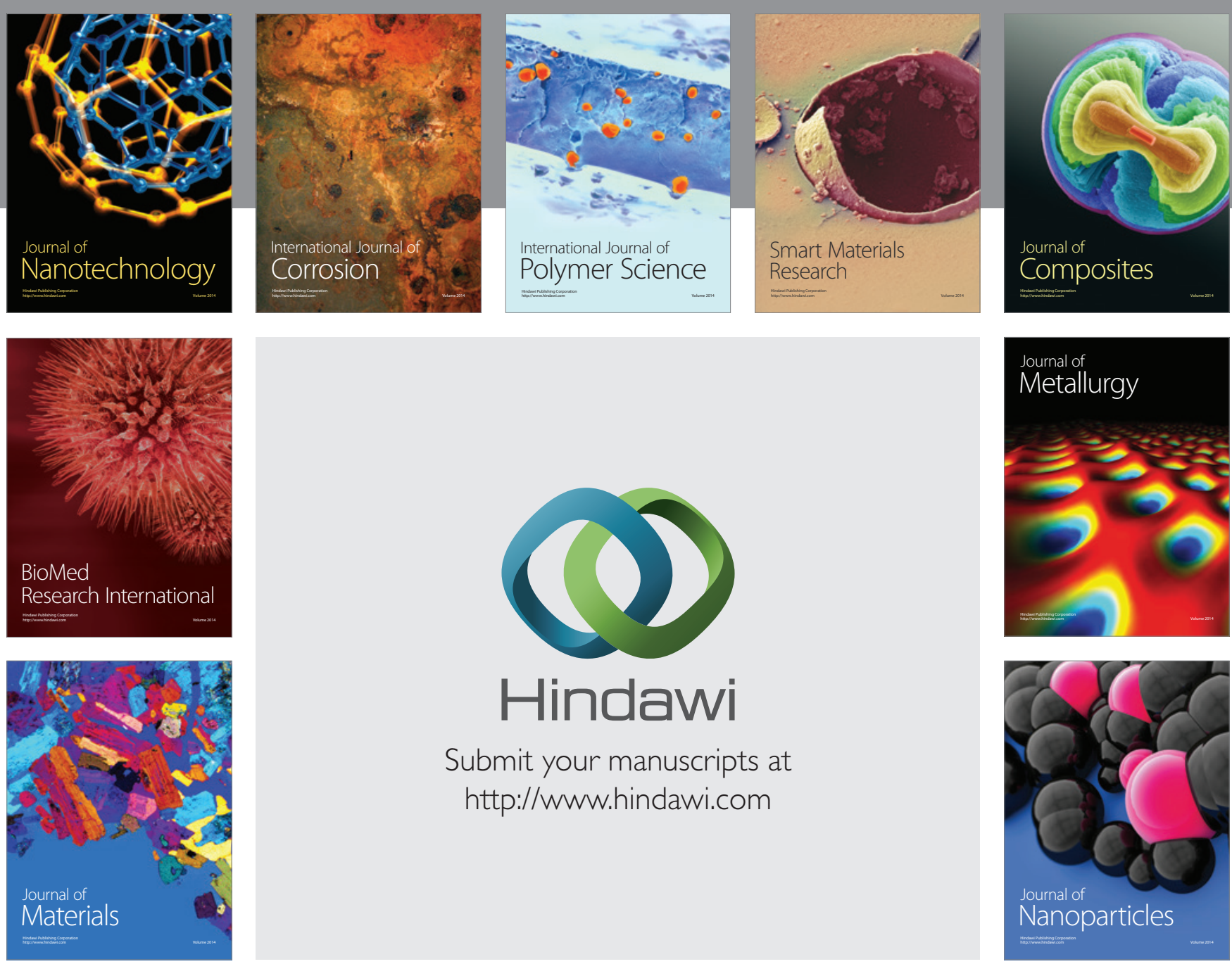

Submit your manuscripts at http://www.hindawi.com
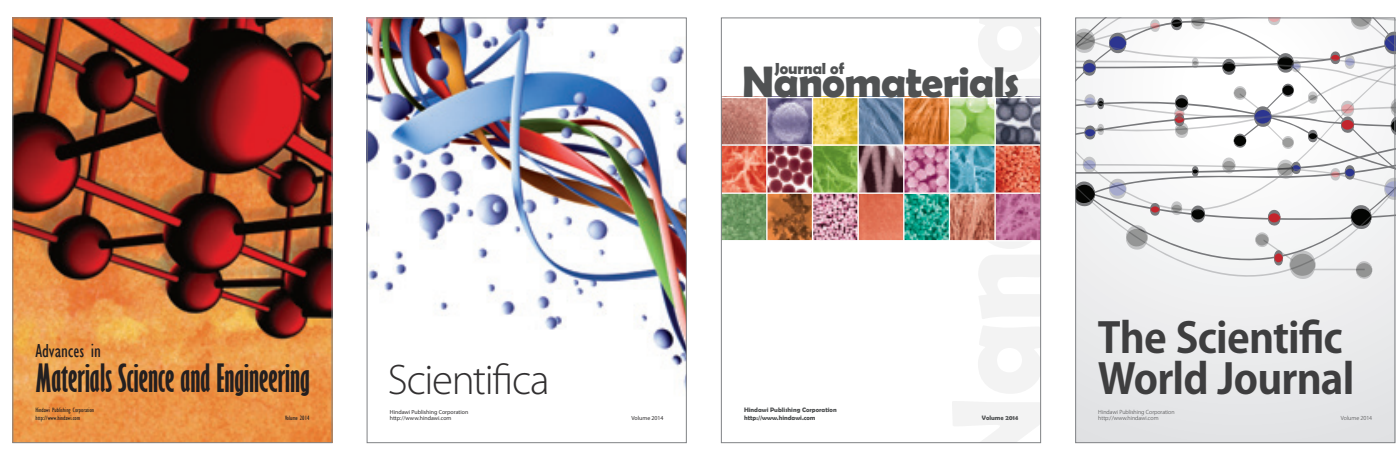

\section{The Scientific World Journal}
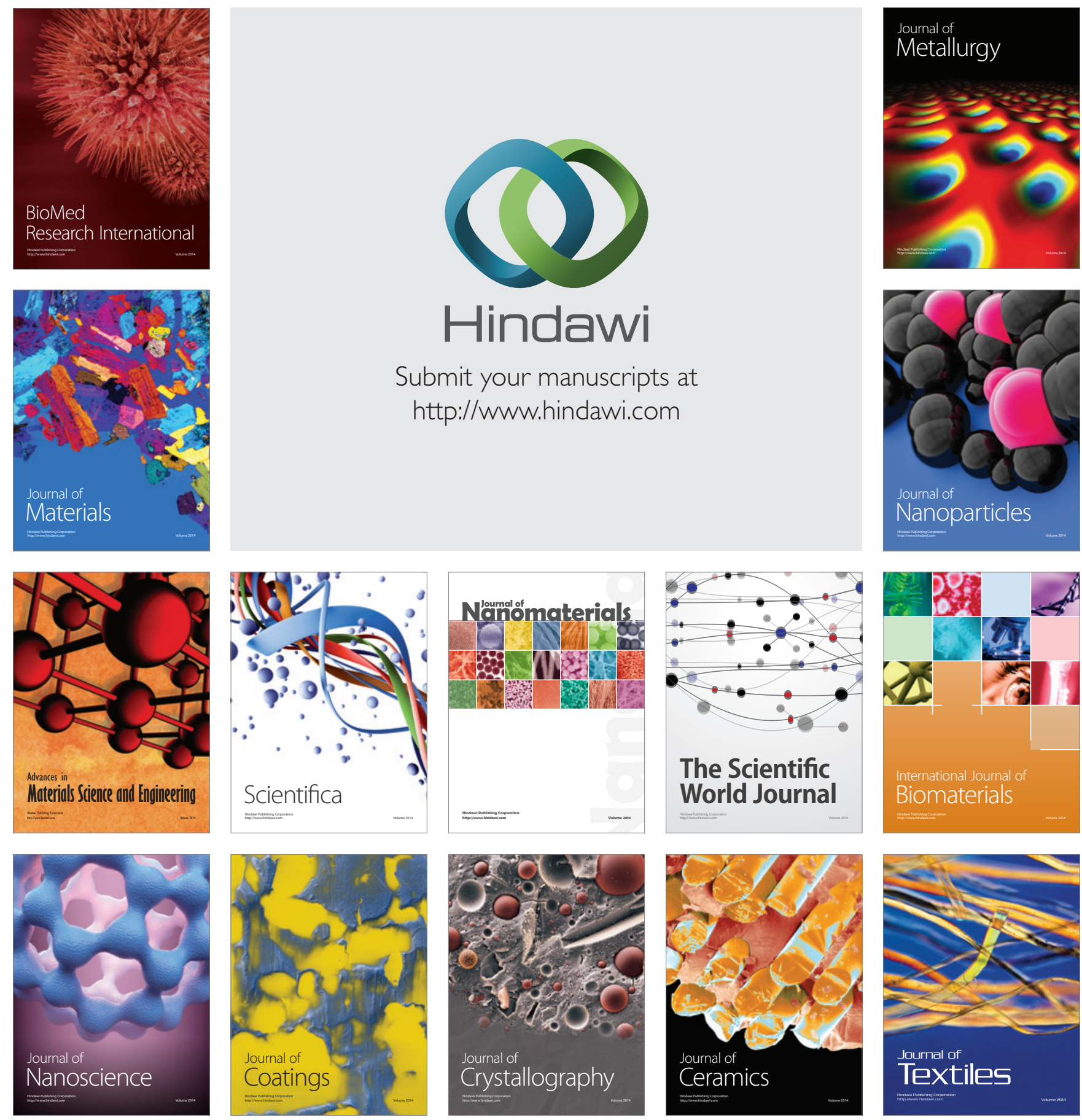